\title{
MODO DE PRODUÇÃO DA EXISTÊNCIA: CATEGORIA CHAVE PARA A COMPREENSÃO DA PROBLEMÁTICA DO LAZER
}

Elza Margarida de Mendonça Peixoto Universidade Federal da Bahia - UFBA

\section{RESUMO}

A partir da crítica aos limites no modo como os estudos do lazer apropriam a noção de trabalho na obra de Marx e Engels, o artigo recupera a estrutura mais ampla na qual esta categoria está inscrita no pensamento daqueles autores, retomando a centralidade da categoria modo de produção da existência enquanto categoria estrutural daquele pensamento. Este movimento é feito com a finalidade de indicar a categoria central para a explicação do movimento histórico real que engendra o lazer enquanto uma prática dos homens que - no capitalismo - encontra-se subordinada - o tempo, a atividade e a subjetividade - à lei econômica do movimento da sociedade moderna, na qual estão em movimento forças que contraditória e dialeticamente estão produzindo outra conjuntura. Palavras Chave: teoria; modo de produção; marxismo; lazer; estudos do lazer.

\section{MODE OF PRODUCTION OF EXISTENCE: CENTRAL CATEGORY TO UNDERSTANDING THE PROBLEM OF LEISURE}

\begin{abstract}
From the critical limits in how leisure studies appropriating the notion of work in the work of Marx and Engels, the article recovers a broader framework in which this category is entered in the thinking of those authors, resuming the centrality of the category mode production of existence as structural category that thought. This movement is done with the purpose of indicating the category central to the explanation of the real historical movement which engenders leisure as a practice of men - capitalism - is subordinated time, activity and subjectivity - the economic law of movement of modern society, in which forces are in motion that are dialectically contradictory and producing another juncture.
\end{abstract}

Key Words: theory; methods; Marxism; leisure; leisure studies

\section{RESUMEN:}

A partir de los límites críticos en cómo los estudios de ocio apropiarse del concepto de trabajo en la obra de Marx y Engels, el artículo se recupera un marco más amplio en el que se introduce en el pensamiento de los autores de esta categoría, la reanudación de la centralidad del modo de categoría la producción de la existencia como categoría estructural que cree. Este movimiento se realiza con la finalidad de indicar la categoría central de la explicación del movimiento histórico real que genera el ocio como una práctica de los hombres - el capitalismo - es subordinada - tiempo, la actividad y la subjetividad - la ley económica de movimiento de la sociedad moderna, en la que las fuerzas están en movimiento que están dialécticamente contradictoria y produciendo otra coyuntura.

Palabras Clave: teoría, los métodos, el marxismo, el ocio, los estudios de ocio 


\section{Introdução}

O levantamento da apropriação da obra de Marx e Engels pelos estudos do lazer no Brasil (PEIXOTO, 2007) evidencia a existência de 107 textos e 68 autores que recorrem ao pensamento de Marx para estabelecer suas posições acerca da problemática do lazer. Estes estudiosos partem da negação ou afirmação da centralidade do trabalho na existência humana, com referências à concepção de trabalho presente no pensamento de Marx. No primeiro caso, esta referência parte de uma ontologia idealista, afirmando que Marx, ao estabelecer a centralidade do trabalho, estava orientado pela ética puritana, não conseguindo se desprender da ode à produtividade. No segundo caso, delineia-se uma ontologia materialista, na qual há reconhecimento da centralidade da produção da existência na obra de Marx, mas este reconhecimento não ultrapassa a dimensão do trabalho explorado. Nos dois casos, a análise da totalidade contraditória e dialética na qual está inscrita a problemática lazer/trabalho fica comprometida pelo próprio processo parcial e fragmentado de apropriação da categoria trabalho na obra de Marx, que se dá duplamente descolada (1) do movimento empreendido pelo autor para apoderar-se da lei econômica de movimento da sociedade moderna - que incluiu estudos sobre a centralidade do trabalho na produção da existência humana e sobre sua característica no modo capitalista de produção -, expresso nos escritos de juventude e de maturidade; (2) do processo histórico concreto, do movimento real que engendra o trabalho estranhado no modo capitalista de produção, cuja expressão máxima é $O$ capital.

A partir da crítica aos limites no modo como os estudos do lazer apropriam a noção de trabalho na obra de Marx e Engels, o artigo recupera a estrutura mais ampla na qual esta categoria está inscrita no pensamento daqueles autores, retomando a centralidade da categoria modo de produção da existência enquanto categoria estrutural daquele pensamento. Este movimento é feito com a finalidade de indicar a centralidade da categoria modo de produção da existência para a explicação do movimento histórico real que engendra o lazer enquanto prática social que os homens realizam no processo de produção de sua existência. Uma prática que no modo capitalista de produção configura-se subordinada - o tempo, a atividade e a subjetividade - à lei econômica de movimento da sociedade moderna.

\section{A categoria teórica que tem norteado os estudos do lazer}

A negação do trabalho tal como ocorre no capitalismo é, provavelmente a constatação mais consensual no âmbito dos estudos do lazer, apresentando-se em duas formulações. Em um extremo, assume a forma imediata de negação do trabalho como espaço de realização humana, e da defesa veemente do lazer como espaço privilegiado desta realização, culminando, no contexto da promessa de fim da sociedade do trabalho propagada no final da década de 60, com a defesa da emergência da sociedade do lazer. Em outro extremo, leva à imediata negação do lazer como campo de ação e de pesquisas, tendo em vista suas profundas conexões compensatórias e funcionalistas com o trabalho explorado, com a circulação e o consumo de mercadorias, com a alienação.

No primeiro caso, a negação do trabalho ocorre desprovida da noção ontológica de atividade vital sem a qual não há existência humana, não há produção da existência humana, não há história. O trabalho é propagado como uma imposição ideológica que visa à acumulação e à riqueza, uma imposição ocorrida no período de transição da sociedade 
tradicional à sociedade moderna. Enquanto imposição ideológica, a luta contra a opressão pelo trabalho aparece como uma questão de simples mudança de idéias. Neste caso a aposta no desenvolvimento do lazer como alternativa de futuro está acompanhada da constatação fenomênica de que não seria possível uma vida satisfatória no lazer sob as amarras do vício da produtividade, adquirido em uma sociedade que fez o elogio do trabalho. Esta constatação pede uma atuação dos profissionais no sentido de uma educação para aprender a viver o tempo livre e desaprender os valores da produtividade (CAMARGO, 1986, 1998), viabilizando a consciência da situação opressiva do trabalho explorado e a construção de alternativas de mudança (no aqui e agora, negando-se o devir), em busca de outra hegemonia baseada na negação dos valores da produtividade e na valorização da fruição do lúdico e da cultura (MARCELLINO, 1983, 1987, 1990).

No segundo caso, são reconhecidos os vínculos da prática social do lazer - e sua propagação ideológica - com a lógica do modo capitalista de produção. Os nexos do lazer com o trabalho alienado, com a recuperação para o trabalho, com a difusão e a propagação do consumo estão devidamente anunciados. A partir deste reconhecimento, evidencia-se uma posição que vai apontar a impossibilidade de o lazer configurar-se como categoria de análise e como problemática social significativa, com abandono de interesse pela temática. Evidencia-se também uma segunda posição que vai explorar as relações entre trabalho e lazer em uma perspectiva funcionalista, visando ao conhecimento dos vínculos entre o que se faz no trabalho e o que se faz no tempo livre, com ênfase no entendimento e no aprimoramento do segundo. Reconhece-se o trabalho explorado e aponta-se a necessidade de investir nos estudos e políticas para o lazer visando à realização humana no tempo livre, já que tal não é possível no tempo de trabalho. Uma terceira posição evidente, mais recente na literatura, vai dedicar-se ao entendimento do trabalho alienado a fim de discutir as possibilidades e limites do lazer nestas condições. É neste lugar que o debate teórico dos estudos do lazer estaciona, desprovido de aprofundamento teórico que viabilize uma compreensão mais rigorosa e radical dos processos históricos que permitem a produção da relação entre trabalho e lazer como uma relação contraditória, dialética e transitória, típica do movimento das forças produtivas e das relações de produção no modo capitalista de produção.

Este impasse teórico, a nosso ver, só pode ser superado com a apropriação da obra de Marx e Engels em busca de uma visão de totalidade sobre o modo de produção capitalista e as correspondentes relações de produção e de circulação (MARX, 1989, p. 5). Este movimento pede a compreensão da articulação das categorias trabalho, trabalho alienado e modo de produção no pensamento dos autores e no movimento real próprio ao capitalismo.

\section{Trabalho e trabalho alienado}

Nas reflexões de Marx presentes nos Manuscritos Econômicos e Filosóficos de 1844, especialmente em $O$ trabalho Estranhado, o trabalho aparece como a atividade vital do homem (MARX, 2003), que atuando sobre a natureza externa e modificando-a, ao mesmo tempo modifica sua própria natureza (MARX, 1989b, p. 202, ENGELS, 1979, p. 215-227). Sendo o trabalho atividade vital - atividade sem a qual não se produz a vida humana, não há História - evidencia-se a necessidade contínua dos homens de realizar o trabalho a fim de produzir as condições de sua existência.

Marx e Engels denunciam que no modo capitalista de produção, o processo de trabalho está marcado pelo estranhamento do homem frente a si mesmo, ao objeto do seu trabalho e à classe que apropria sua produção. O trabalho encontra-se de tal forma 
deteriorado e degradado que não apresenta perspectiva de satisfação de qualquer interesse do trabalhador. Estas conclusões postas nos Manuscritos econômico-filosóficos de 1844 representam a síntese da situação da classe trabalhadora, mas são apenas os passos iniciais para a explicação de sua condição no modo capitalista de produção, não sendo suficiente para o entendimento dos processos históricos e do movimento real que a determina.

Nos prefácios de $O$ capital se torna evidente o objetivo mais amplo de Marx: apoderar-se dos pormenores do modo de produção capitalista e de suas correspondentes relações de produção e de circulação (MARX, 1989, p. 5). Suas observações acerca do método de exposição e do método de pesquisa permitem reconhecer $O$ Capital como a obra síntese de um estudo que toma toda a vida do autor desde a década de $1840^{1}$. Marx almejava expor o movimento real do modo de produção capitalista, mas isto só se tornou possível depois de longos anos de investigação.

É a análise dos pormenores do modo de produção capitalista que permite a Marx e Engels apreender a totalidade contraditória e dialética em que está inscrita a miséria da classe trabalhadora. $\mathrm{O}$ trabalho estranhado, que aparece para muitos como causa exclusiva da opressão do trabalhador, é produto de relações de produção (1) nas quais o processo produtivo como um todo e as forças produtivas estão sob a propriedade privada da burguesia; (2) nas quais o trabalho realiza-se condicionado e determinado pelos interesses do burguês, na condição histórica de proprietário dos meios de produção; (3) nas quais o trabalhador, expropriado dos meios de produção (a terra enquanto objeto do trabalho e os meios de trabalho, o instrumental de trabalho - MARX, 1989, p. 202) fica aprisionado a relações de produção que o oprimem e das quais não consegue desprender-se enquanto indivíduo, mas apenas enquanto classe organizada para si.

A maior parte dos estudiosos do lazer que apropriam da obra de Marx e Engels não consegue apreender este movimento, em virtude, fundamentalmente, de estarem se apropriando desta obra (1) através de intérpretes; (2) excluindo os estudos de Engels; (3) apropriando-se de uma ou outra obra de Marx; (4) na apropriação da obra de Marx, apropriando-se de uma ou outra categoria descontextualizada do conjunto de que faz parte. Ao se aprofundam na apropriação da obra de Marx e Engels concentram-se na exposição do significado do trabalho alienado para o homem, desprezando a totalidade da análise por eles empreendida, na qual se configura o projeto de revolução do modo como os homens estão produzindo e reproduzindo sua existência. O embate reforma/revolução nos estudos do lazer, paraliza-se, de um lado, na opção pela defesa e disseminação de políticas públicas paliativas, incapazes de transformar por si só as condições objetivas geradoras da exclusão do direito ao lazer (por exemplo, o recuo do processo de redução da jornada de trabalho sem redução do salário, uma reivindicação histórica dos trabalhadores e a consequiente onda de desemprego); de outro lado, negando a contradição dialética estranhamento/possibilidades de superação, nega a crítica madura das possibilidades concretas da prática do lazer. A nosso ver, tais problemas decorrem da apropriação parcial e fragmentada do único referencial teórico que permite explicar: (1) o processo histórico que produz o lazer como prática, política e conhecimento; (2) os nexos e contradições nos quais se inscreve o lazer no contexto do modo capitalista de produção; (3) as perspectivas objetivas de atuação neste campo. Este referencial é a Concepção Materialista e Dialética da História, e o eixo estruturante deste referencial é a noção de modo de produção. Como esta categoria aparece na obra de Marx e Engels e quais as suas possibilidades explicativas? Adiantamos que a percepção do movimento que Marx e Engels realizam para o entendimento das condições objetivas nas quais se efetiva a produção da existência (o trabalho) só é possível a partir da visão de conjunto das obras dos dois autores. 


\section{Modo de produção capitalista}

A compreensão da noção de modo de produção na obra de Marx e Engels pede a retomada, no texto dos próprios autores, do processo de sua construção. No Prefácio à Contribuição à crítica da economia política, após um primeiro parágrafo no qual informa ao leitor o modo como examina o sistema da economia burguesa e sua opção por deixar o texto tal como no método de investigação, Marx recuperará as condições históricas nas quais se vê obrigado a posicionar-se sobre os "interesses materiais" ou "questões econômicas", relatando que enquanto redator da Rheinische Zeitund deparara-se com debates que pediam posicionamentos para os quais não se sentia competente. Esta situação o faz retirar-se da cena política dedicando-se aos estudos. Descreve:

[...] Nas minhas pesquisas cheguei à conclusão de que as relações jurídicas - assim como as formas do Estado - não podem ser compreendidas por si mesmas, nem pela dita evolução geral do espírito humano, inserindo-se pelo contrário nas condições materiais de existência de que Hegel, à semelhança dos ingleses e franceses do século XVIII, compreende o conjunto pela designação de "sociedade civil"; por seu lado, a anatomia da sociedade civil deve ser procurada na economia política. Tinha começado o estudo desta em Paris, continuando-o em Bruxelas, para onde emigrei após uma sentença de expulsão do $\mathrm{Sr}$. Guizot. A conclusão geral a que cheguei e que, uma vez adquirida, serviu de fio condutor dos meus estudos, pode formular-se resumidamente assim: na produção social da sua existência, os homens estabelecem relações determinadas, necessárias, independentes da sua vontade, relações de produção que correspondem a um determinado grau de desenvolvimento das forças produtivas materiais. O conjunto destas relações de produção constitui a estrutura econômica da sociedade, a base concreta sobre a qual se eleva uma superestrutura jurídica e política e a qual correspondem determinadas formas de consciência social. $\mathrm{O}$ modo de produção da vida material condiciona o desenvolvimento da vida social, política e intelectual em geral. Não é a consciência dos homens que determina o seu ser; é o seu ser social que, inversamente, determina a sua consciência. Em certo estágio de desenvolvimento, as forças produtivas materiais da sociedade entram em contradição com as relações de produção existentes ou, o que é a sua expressão jurídica, com as relações de propriedade no seio das quais se tinham movido até então. De formas de desenvolvimento das forças produtivas, estas relações transformam-se no seu entrave. Surge então uma época de revolução social. A transformação da base econômica altera, mais ou menos rapidamente, toda a imensa superestrutura. Ao considerar tais alterações é necessário sempre distinguir entre a alteração material - que se pode comprovar de maneira cientificamente rigorosa - das condições econômicas de produção, e as formas jurídicas, políticas, religiosas, artísticas ou filosóficas, em resumo, as formas ideológicas pelas quais os homens tomam consciência deste conflito, levando-o às suas últimas conseqüências. Assim como não se julga um indivíduo pela idéia que ele faz de si próprio, não se poderá julgar uma tal época de transformação pela mesma consciência de si; é preciso, pelo contrário, explicar esta consciência pelas contradições da vida material, pelo conflito que existe entre as forças produtivas sociais e as relações de produção. Uma organização social nunca desaparece antes que se desenvolvam todas as 
forças produtivas que ela é capaz de conter; nunca relações de produção novas e superiores se lhe substituem antes que as condições materiais de existência destas relações se produzam no próprio seio da velha sociedade. É por isso que a humanidade só levanta os problemas que é capaz de resolver e assim, numa observação atenta, descobrir-se-á que o problema só surgiu quando as condições materiais para o resolver já existiam ou estavam, pelo menos, em vias de aparecer [...] as forças produtivas que se desenvolvem no seio da sociedade burguesa, criam ao mesmo tempo as condições materiais para resolver esta contradição (MARX, 1977, p. 24-25).

Ressaltando que Engels - "com quem, desde a publicação do seu genial esboço de uma contribuição para a crítica das categorias econômicas nos Deutsch Französische Jahrbücher, tenho mantido por escrito uma constante troca de idéias" - havia chegado por outras vias (...) a mesmo resultado, através de seu livro A situação da classe trabalhadora em Inglaterra (s/d), Marx dirá:

[...] resolvemos trabalhar em conjunto, a fim de esclarecer o antagonismo existente entre a nossa maneira de ver a concepção ideológica da filosofia alemã ; tratava-se, de fato, de um ajuste de contas com a nossa consciência filosófica anterior. Este projeto foi realizado sob a forma de uma crítica da filosofia pós-hegeliana. O manuscrito, dois grandes volumes in-octavo, estava há muito no editor na Vestefália, quando soubemos que novas circunstâncias já não permitiam sua impressão. De bom grado abandonamos o manuscrito à crítica corrosiva dos ratos, tanto mais que tínhamos atingido o nosso fim principal, que era enxergar claramente as nossas idéias. Dos vários trabalhos dispersos desta época em que apresentamos as nossas opiniões sobre os diversos assuntos, mencionarei apenas o Manifesto do Partido Comunista, redigido em colaboração com Engels, e o Discurso sobre o Livre-Câmbio publicado por mim. Os pontos decisivos das nossas concepções foram cientificamente esboçados pela primeira vez, ainda que de forma polêmica, no meu texto contra Proudhon publicado em 1847: Miséria da Filosofia, etc. A impressão de uma dissertação sobre o Trabalho assalariado, escrita em alemão e reunindo as conferências sobre este tema que proferi na Associação dos Operários Alemães de Bruxelas, foi interrompida pela Revolução de Fevereiro a que se seguiu a minha expulsão da Bélgica (MARX, 1977, p. 25-26).

Nestas passagens, Marx sinaliza a seus leitores (1) a trajetória que percorre para produzir a Contribuição à crítica da economia política e $O$ capital; (2) a teoria que norteia os estudos que vai realizar; (3) a parceria com Friedrich Engels na autoria desta teoria; (4) as obras nas quais esta teoria vem sendo produzida. Munidos destas armas fornecidas pelo próprio autor, podemos acompanhar (a) a teoria explicativa que identificamos como teoria central para apoderar-mo-nos da problemática do lazer; (b) o processo de produção da explicação para o capitalismo como o modo moderno pelo qual os homens estão produzindo sua existência.

No manuscrito entregue “à crítica corrosiva dos ratos”, A Ideologia Alemã, há uma exposição de elementos particulares desta teoria geral de que Marx faz a síntese no Prefácio acima referido. Nesta obra, Marx e Engels enfatizam que suas premissas são os indivíduos reais, a sua ação e as suas condições materiais de existência, e que estas premissas são verificáveis por vias puramente empíricas (1974, p. 18). Em seu 
pensamento, a história - única ciência - evidencia-se como produção dos homens no processo de produzir sua existência, explicitando que a primeira condição para que exista a história é a existência de seres humanos vivos (MARX e ENGELS, 1974, p. 18) e o primeiro fato histórico é que estes homens, para permanecerem vivos, necessitam produzir e reproduzir os meios que permitam satisfazer necessidades como comer, abrigar-se, vestirse.

A produção da própria vida material é um fato histórico, a condição fundamental de toda a história, um ato que é necessário, tanto hoje como há milhões de anos, executar dia a dia, hora a hora, a fim de manter os homens vivos. Em qualquer concepção histórica, é primeiro necessário observar este fato fundamental em toda a sua importância e extensão e colocá-lo no lugar que lhe compete (MARX e ENGELS, 1974, p. 33).

Esta produção da vida material não ocorre de modo isolado. Os homens produzem socialmente, renovando os meios necessários à sua existência e reproduzindo outros homens, o que coloca a produção da vida além de uma relação que os homens estabelecem com a natureza: uma relação que os homens estabelecem com outros homens (MARX e ENGELS, 1974, p. 33).

Essa tese será especialmente desenvolvida em A origem da família, da propriedade privada e do Estado (1995), quando Engels, a partir de apontamentos de Marx sobre a obra de Lewis H. Morgan, fará uma estudo criterioso sobre as formas da família em diferentes momentos históricos, e as alterações que esta vai sofrendo conforme se transforma a produção da existência. No Prefácio à primeira edição/1884, Engels dirá:

De acordo com a concepção materialista, o fator decisivo na história é, em última instância, a produção e a reprodução da vida imediata. Mas essa produção e essa reprodução são de dois tipos: de um lado, a produção de meios de existência, de produtos alimentícios, habitação, e instrumentos necessários para tudo isso; de outro lado, a produção do homem mesmo, a continuação da espécie. A ordem social em que vivem os homens de determinada época ou determinado país está condicionada por essas duas espécies de produção; pelo grau de desenvolvimento do trabalho, de um lado, e da família, de outro (ENGELS, 1995, p. 2).

O modo de produção (ou estágio de desenvolvimento industrial) está permanentemente ligado a um estado social determinado (um modo de cooperação). $\mathrm{O}$ modo de cooperação é uma força produtiva juntamente com as diversas invenções que o homem põe entre si e a natureza com a finalidade de facilitar o trabalho de extrair da terra o objeto de trabalho, armazenar e transportar estes objetos de trabalho para os locais nos quais vão sendo transformados em matérias-primas para outros processos de trabalho. Para Marx e Engels, o conjunto de forças produtivas acessíveis aos homens em um dado momento histórico determina o estado social. E para compreender qualquer estado social se deve conseqüentemente estudar e elaborar a "história dos homens" em estreita correlação com a história da indústria e das trocas (MARX e ENGELS, 1974, p. 33).

Neste processo, evidencia-se a noção de trabalho como atividade vital, tal como anunciado por Marx em 1844, e, mais tarde, precisada por Engels como a condição fundamental de toda a vida humana; em um grau tão elevado que, num certo sentido, pode-se dizer: o trabalho, por si mesmo, criou o homem (ENGELS, 1979, p. 215). Ainda em A ideologia alemã, na crítica à visão fenomênica de Feuerbach, os dois autores dirão: 
Essa actividade, esse trabalho, essa criação material incessante dos homens, essa produção é a base de todo o mundo sensível tal como hoje existe, e a tal ponto que se o interrompêssemos apenas por um ano, Feuerbach não só encontraria enormes modificações no mundo natural como até lamentaria a perda de todo o mundo humano e da sua própria faculdade de contemplação, ou mesmo da sua própria existência (MARX e ENGELS, 1974, p. 32).

Mas o trabalho, olhado isoladamente, não é suficiente para explicar as complexas relações de produção em qualquer período histórico, inclusive, porque o trabalho transforma-se conforme se transforma e evolui o modo de produção. Esta transformação aparece claramente quando observamos as mutações no trabalho decorrentes do avanço das forças produtivas e das correspondentes relações de produção. Sob esta referência, está em questão a percepção de que no mundo que o trabalho cria, o próprio trabalho tem de ser contextualizado. É por esta razão que o modo de produção (as forças produtivas e as correspondentes relações de produção engendradas pelo trabalho) explica a forma do trabalho.

Ora, esta mesma análise histórica que se apóia sobre o modo como os homens estão produzindo sua existência para explicar o processo concreto de desenvolvimento do trabalho permite, sob as mesmas bases teóricas, explicar o desenvolvimento do tempo livre em cada momento histórico, em seus pormenores e conexões com o trabalho. No estudo do modo como os homens vão vivenciar o tempo livre em cada momento histórico, é possível compreender a forma do lazer em cada modo de produção. Com esta proposição focamos uma alteração essencial: passar da análise isolada das práticas e contextos - predominante nos estudos do lazer -, para a análise ampliada dos nexos e contradições destas práticas de lazer com o a totalidade do modo de produção, ou seja, as forças produtivas e as correspondentes relações de produção vigentes em um dado momento histórico, engendradas pelo trabalho passado.

Sob esta perspectiva, não se trata de conceituar o lazer, de definir o lazer em si mesmo, a partir de atividades, atitudes ou subjetividades vivenciadas por este ou aquele indivíduo ou segmentos de indivíduos. A identificação dos nexos e contradições nos quais o lazer está inscrito está ali no mesmo lugar das relações de trabalho, no modo como são apropriados e distribuídos os bens socialmente produzidos, na divisão social do trabalho, em última instância, no modo como está organizado em cada momento histórico a produção da existência.

Ali, no próprio modo de produção, entre as forças produtivas, encontra-se a produção do conhecimento (a ser veiculada pela educação) e o lazer, entendido como o tempo livre para a fruição dos bens socialmente produzidos pela humanidade. Nas relações capitalistas estes bens estão concentrados nas mãos da classe que se apropria privadamente dos meios de produção e de todos os seus produtos, a classe que impulsionou os processos revolucionários do século XVIII, a burguesia, a classe dos capitalistas (MARX, 1998). Ainda em A ideologia alemã, encontramos os rudimentos desta tese, quando Marx e Engels analisam o ponto de ebulição que provoca revoluções nos modos de produção:

[...] os três momentos constituídos pela força produtiva, o estado social e a consciência podem e devem necessariamente entrar em conflito entre si pois, através da divisão do trabalho, torna-se possível o que se verifica efectivamente, que a actividade intelectual e material - o gozo e o trabalho, a produção e o consumo, caibam a indivíduos distintos; então, a possibilidade de que esses elementos não entrem em conflito reside 
unicamente na hipótese de acabar de novo com a divisão do trabalho (MARX e ENGELS, s/d, p. 37-38).

Marx e Engels são taxativos ao dizer, no processo de crítica aos novos hegelianos que achavam estar revolucionando a realidade com a crítica da religião: Não é a crítica mas sim a revolução que constitui a força motriz da história, da religião, da filosofia ou de qualquer outro tipo de teorias (MARX e ENGELS, 1974, p. 49). Mas de que revolução estão a falar Marx e Engels? Da revolução que permitirá a superação dos obstáculos históricos à evolução da humanidade: a apropriação privada dos meios de produção, que impede aos que efetivamente produzem o acesso aos bens que produzem, e, mais que isto, a realização das potencialidades que o gênero levou milênios para desenvolver. A revolução é a única saída, a saída para a qual são impelidos os homens que se encontram em cadeias radicais:

Para que ela (esta alienação) se transforme num poder "insuportável", quer dizer, num poder contra o qual se faça uma revolução, é necessário que tenha dado origem a uma massa de homens totalmente "privada de propriedade", que se encontre simultaneamente em contradição com um mundo de riqueza e de cultura com existência real; ambas as coisas pressupõem um grande aumento da força produtiva, isto é, um estádio elevado de desenvolvimento (MARX e ENGELS, 1974, p. 41-42).

Nas contradições internas engendradas no seio do capitalismo encontram-se as condições para a sua superação. O tempo livre, que em cada momento histórico, conforme com a divisão social do trabalho em cada momento histórico, é apropriado por segmentos privilegiados da população, durante o final do século XIX e primeira metade do século XX, aparece, tomado pelo individualismo, como ampliação generalizada de espaço/tempo privado para a fruição da atividade livre para si. Mas, sob a ordem do capital, todas as necessidades, todas as conquistas são convertidas em favor da acumulação. O capital responde às lutas dos trabalhadores pela redução da jornada de trabalho, com o desemprego, a intensificação da jornada dos empregados, a injunção ao consumo frenético e desenfreado de bens, serviços e fragmentos de informações. Entende-se que o reconhecimento deste conflito de interesses que funda o modo de produção capitalista é central para a explicação da contraditória relação trabalho x lazer. É na luta de classes, no confronto de projetos contraditórios, antagônicos e conflitantes provenientes da burguesia e da classe trabalhadora, que devemos buscar a explicação para a problemática do lazer.

No Brasil da primeira metade do século XX deflagra-se a preocupação com a ocupação do tempo livre da classe trabalhadora. Para o entendimento deste movimento, assume centralidade a análise da forma específica como vai desenvolver-se a produção da existência na formação social brasileira. Neste contexto histórico, trata-se de compreender a totalidade das relações contraditórias e dialéticas (1) nas quais o trabalho para a produção da existência se dá alienado; (2) nas quais a fruição do tempo livre (e nele, o lazer) aparece, ao mesmo tempo, como continuidade (na forma do lazer alienado, reduzido ao consumo obsessivo e obcecado de práticas, objetos e símbolos) e possibilidade de ruptura (na forma da constatação da condição miserável na qual vivem os homens no modo capitalista de produção). 


\section{A título de Considerações Finais: Práticas, políticas e produção do conhecimento referente aos estudos do lazer no Brasil na primeira metade do século XX - à luz da teoria marxiana.}

O recurso teórico à categoria modo de produção permite explicar as motivações do Estado e de educadores brasileiros para a produção do conhecimento e das políticas públicas de caráter funcionalista que vão ser disseminadas e implementadas nas 5 primeiras décadas do século XX. Intensamente focadas na determinação das atividades consideradas mais valorosas para a ocupação do tempo livre do trabalhador, esta produção do conhecimento que subsidiava a política de educação para o lazer, encontrava-se profundamente marcada pela intenção de realizar a conformação dos interesses dos trabalhadores aos interesses burgueses pela industrialização do Brasil. A nosso ver, a visão funcionalista que predomina nestas proposições possui profundas conexões com a predominância dos interesses da burguesia em um momento histórico que necessita defender ferrenhamente o pacto social entre trabalho e capital, a fim de garantir a implementação e a consolidação de seu projeto de classe que visa, em última instância, à acumulação. A visão funcionalista predominante na produção do conhecimento referente aos estudos do lazer no Brasil é uma das expressões ideológicas dos esforços de solucionar os conflitos presentes nas relações de produção decorrentes do modo como estão sendo apropriadas e distribuídas as forças produtivas.

É no contexto das orientações para a análise da ideologia postas em A Ideologia Alemã e em Contribuição à crítica da economia política, que se torna possível compreender como a proposição de políticas públicas voltadas à ocupação do tempo livre do trabalhador (de seus filhos e familiares), no Brasil da primeira metade do século XX, está profundamente associada ao esforço (1) de contenção das lutas dos trabalhadores, principalmente, nas décadas de 1920, 30 e 40; e (2) de conformação dos trabalhadores aos interesses da burguesia brasileira, direcionados, naquela ocasião ao projeto de industrialização do Brasil. Esta proposição de políticas públicas reflete um embate que Braverman precisa com clareza ao dizer que:

A transformação da humanidade trabalhadora em uma "força de trabalho", em "fator de produção", como instrumento do capital, é um processo incessante e interminável. A condição é repugnante para as vítimas, seja qual for o seu salário, porque viola as condições humanas do trabalho; e uma vez que os trabalhadores não são destruídos como seres humanos, mas simplesmente utilizados de modo inumano, suas faculdades críticas, inteligentes e conceptuais permanecem sempre, em algum grau, uma ameaça ao capital, por mais enfraquecidas ou diminuídas que sejam. Além do mais, o modo capitalista de produção está continuamente se expandindo a novas áreas de trabalho, inclusive àquelas recentemente criadas pelo avanço tecnológico e o emprego do capital a novas indústrias. Está, ainda, sendo continuamente requintado e aperfeiçoado, de modo que sua pressão sobre os trabalhadores é incessante. Ao mesmo tempo, a habituação dos trabalhadores ao modo capitalista de produção deve ser renovada a cada geração, tanto mais que as gerações surgidas sob o capitalismo não são formadas dentro da matriz da vida de trabalho, mas jogadas no trabalho vindas de fora, por assim dizer, após um prolongado período de adolescência durante a qual são mantidas na reserva. A necessidade de ajustar o trabalhador ao trabalho em sua forma capitalista, de superar a resistência natural intensificada pela tecnologia mutável e alternante, relações sociais antagônicas e a 
sucessão de gerações, não termina com a "organização científica do trabalho", mas se torna um aspecto permanente da sociedade capitalista (BRAVERMAN, 1987, p. 124).

O projeto de ocupação do tempo livre, no Brasil, está profundamente associado a este movimento. Esta intenção é visível nas introduções dos Manuais de Recreação e nos documentos produzidos pelos órgãos que receberam dos governos a tarefa de desenvolvimento de políticas ${ }^{2}$.

Finalmente, a título de apontamentos para futuros estudos, afirma-se que a categoria modo de produção na obra de Marx e Engels contribui radicalmente para pensar a problemática do lazer, na medida em que permite: (1) explicar os conteúdos do lazer como resultado da atividade vital do homem no processo de produzir e reproduzir os bens necessários à sua existência, bens que podem ser úteis, ao mesmo tempo, para satisfazer necessidades de produção, de subsistência ou lúdicas; (2) explicar a forma do trabalho e do tempo livre em diferentes momentos históricos; (3) explicar como, no modo capitalista de produção, o tempo livre é resultado do desenvolvimento das forças produtivas, mas, fundamentalmente, do grau de organização e poder da classe trabalhadora, o que aponta que o tempo livre sofre pressão para a sua redução quando a classe trabalhadora está mais desorganizada, uma pressão em favor do tempo produtivo, da precarização e do desemprego (CUNHA, 1987); (4) explicar como, no modo capitalista de produção, a geração do tempo livre é pensada também para garantir a disponibilidade para o consumo, convertendo-se em mercadoria para a circulação de mercadoria (FALEIROS, 1980); (5) explicar que, de caráter funcionalista, e focadas na ocupação do tempo livre, as políticas até aqui implementadas visam amenizar as tensões entre capital e trabalho (basta considerar a baixíssima qualidade do ensino, que despreza a transmissão do patrimônio que a humanidade acumulou no âmbito da arte, da literatura, da música, produzidas no momento privilegiado de tempo livre para uma atividade livre de uma pequena parcela da população); (6) explicar que a produção do conhecimento referente aos estudos do lazer no Brasil expressa o movimento da luta de classes que vem se dando na formação social brasileira, destacando-se ai a opção predominante dos intelectuais que produzem os estudos do lazer pelo atendimento dos interesses de mercado. Destes apontamentos, muitos deles já indicados na produção de Cunha e Faleiros, na década de 80, podem derivar saltos qualitativos em uma produção do conhecimento que, com poucas exceções, se perde no fragmento.

\section{Referências}

BRAVERMAN, Harry. Trabalho e capital monopolista. 3 ed. Rio de Janeiro: LTC, 1987.

CAMARGO, Luiz Octávio de Lima. O que é lazer. São Paulo: Brasiliense, 1986.

CAMARGO, Luiz Octávio de Lima. Educação para o lazer. São Paulo: Moderna, 1998a.

CUNHA, Newton. A felicidade imaginada: a negação do trabalho e do lazer. São Paulo: Brasiliense, 1987.

ENGELS, Federico. A origem da família, da propriedade privada e do Estado. 13 ed. Rio de Janeiro: Bertrand Brasil, 1995.

ENGELS. Friedrich. A situação da classe trabalhadora na Inglaterra. Portugal: Editorial Presença; Brasil: Martins Fontes, s/d 
ENGELS, Friedrich. Esboço de uma crítica da economia política. Temas de ciências humanas, São Paulo, n. 5, p. 1-29, 1979.

FALEIROS, M. I. L. Repensando o lazer. Perspectiva, São Paulo, n. 3, p. 51-65, 1980.

MARCELLINO, Nelson Carvalho. Lazer e educação. Campinas: Papirus, 1987.

MARCELLINO, Nelson Carvalho. Lazer e humanização. Campinas: Papirus, 1983.

MARCELLINO, Nelson Carvalho. Pedagogia da animação. Campinas: Papirus, 1990.

MARINHO, Inezil Penna. Educação Física, Recreação e Jogos. São Paulo: Companhia Brasil Editora Nacional, 1981.

MARX, Carlos. GRUNDRISSE: lineamentos fundamentales para la crítica de la economía política (1857-1858). México: Fondo de Cultura Económica, 1985. (2 vol.)

MARX, Carlos. Los debates de la VI Dieta Renana: Debates sobre la ley castigando los robos de leña. In: MARX, Carlos; ENGELS, Federico. Obras Fundamentales: Carlos Marx: Escritos de Juventud. México: Fondo de Cultura Económica, 1982. p. 248-283. (Volume 1).

MARX, Karl. Contribuição à crítica da economia política. São Paulo: Martins Fontes, 1977.

MARX, Karl. Crítica ao programa de Gotha. In: MARX, Karl. ENGELS, Friedrich. Obras escolhidas. São Paulo: Alfa-ômega, 1980b.

MARX, Karl. O Capital. Livro 3. Volume VI. Rio de Janeiro: Civilização Brasileira, s/d (b).

MARX, Karl. O Capital. Livro 1. Volume I. Rio de Janeiro: Bertrand Brasil, 1989a.

MARX, Karl. O Capital. 12 ed. Livro 1. Volume II. Rio de Janeiro: Bertrand Brasil, 1989b.

MARX, Karl. O Capital. 4 ed. Livro 2. Volume III. São Paulo: DIFEL, 1983.

MARX, Karl. O Capital. Livro 3. Volume IV. Rio de Janeiro: Civilização Brasileira, s/d (a).

MARX, Karl. O Capital. 4 ed. Livro 3. Volume V. São Paulo: DIFEL, 1985.

MARX, Karl. Trabalho alienado e superação positiva da auto-alienação humana. In: FERNANDES, Florestan. Marx e Engels: História. São Paulo: Ática, 1989c.

MARX, Karl. Trabalho Estranhado (extrato). Idéias, Campinas, Ano 9 (2), 10 (1), p. 455-472, 2003.

MARX, Karl. Trabalho estranhado e propriedade privada. In: Manuscritos econômico-filosóficos. São Paulo: Boitempo, 2004 P. 79-90.

MARX, Karl; ENGELS, Friedrich. A ideologia alemã. Porto/ São Paulo: Editorial Presença/Livraria Martins Fontes, 1974. 2 v.

MARX, Karl; ENGELS, Friedrich. Manifesto comunista. São Paulo: Boitempo, 1998.

PITHAN E SILVA, N. Recreação. 2 ed. São Paulo: Cia. Brasil Editora, 1971.

SUSSEKIND, A.; MARINHO, I. P.; GÓES, O. Manual de recreação: orientação dos lazeres do trabalhador. Rio de Janeiro: Ministério do Trabalho, Indústria e Comércio, 1952. 
SUSSEKIND, Arnaldo. Recreação operária. Rio de Janeiro: Ministério do Trabalho, Indústria e Comércio, 1948.

SUSSEKIND, Arnaldo. Trabalho e recreação: fundamentos, organização e realizações da S.R.O. Rio de Janeiro: Ministério do Trabalho, Indústria e Comércio, 1946.

\section{Notas}

1 “É mister, sem dúvida, distinguir, formalmente, o método de exposição do método de pesquisa. A investigação tem de apoderar-se da matéria, de seus pormenores, de analisar suas diferentes formas de desenvolvimento, e de perquirir a conexão íntima que há entre elas. Só depois de concluído esse trabalho, é que se pode descrever, adequadamente, o movimento real. Se isto se consegue, ficará espelhada, no plano ideal, a vida da realidade pesquisada, o que pode dar a impressão de uma construção à priori” (MARX, 1989, p. 16).

${ }^{2}$ Ver Sussekind, Marinho e Pithan e Silva.

Recebido: $\quad$ junho/13 $\quad$ Aprovado: abril/14 